\title{
Members, Members and More Members
}

James A. Yoder

National Science Foundation. Arlington, Virginia USA

The theme of this column should be obvious from the title, but let me digress a moment before getting to the main point. Over the past few years, TOS and our magazine, Oceanography, established new identities with important consequences for the broader ocean community. We have a new meeting format developed in cooperation with OI Americas and The Joint Ocean Forum. Its debut last year in Miami Beach attracted 350 exhibitors and 3300 visitors. TOS ran the scientific conference. The Second Joint Ocean Forum will be held 4-6 June 2003 at the Morial Convention Centre, New Orleans. TOS will again run the conference component of the joint forum, and the talks and posters will cover marine science, technology, operational oceanography, policy and all levels of marine science education. We anticipate that other smaller meetings and workshops will join the forum. This will be a new and different meeting experience for you: not your father's AGU. Many of our members enjoyed the Paris TOS meeting of a few years ago and have encouraged the TOS Council to "internationalize". We like our alliance with OI Americas and plan to continue a biannual meeting with them for the foreseeable future. We are also starting to explore additional venues for special topic meetings, perhaps in Europe or elsewhere.

Oceanography has also developed a new identity with sponsored issues focused on special topics, as well as a new layout and new features. In addition, we are back to publishing 4 issues per year. Publishing thematic issues is a unique role for Oceanography, and we want to continue this role for the future. We also want to continue to publish 4 issues per year, as TOS members want more pages and issues (such as this one) dedicated to unsolicited manuscripts. A good balance might be 2 sponsored and 2 unsponsored issues per year.

That brings me back to the main point of this article: membership. We think our magazine and our new meeting format (which retains the best features of our original meeting format) fill an important niche. In particular, we believe we are different from, although complementary to, AGU, ASLO, GSA and other societies of which most of you are also members. The TOS Council is also considering plans to respond to new ideas that are popular with our members, such as another meeting in Europe. To sustain our current activities and to develop plans for new ones requires a modest increase in resources. We are happy to accept contributions (cash preferred), but we would rather increase resources by increasing membership.
Eric Hartwig will soon take over as TOS President, so this is my final column. My last comment to you as President of TOS is a plea to help us increase TOS membership. Helping us do this is not hard to do: make an announcement at a faculty or other meeting, circulate membership forms, show the magazine to your colleagues, students and employees and so on. If each of our efforts led to one additional TOS member or student member, TOS can do everything mentioned above and more.

(The views expressed in this column are those of the author and do not necessarily reflect the position of the National Science Foundation.)

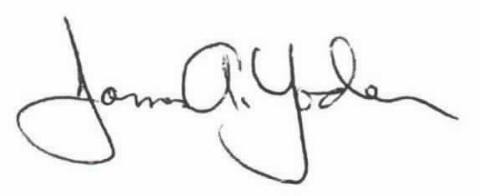

\section{Letter to the Editor}

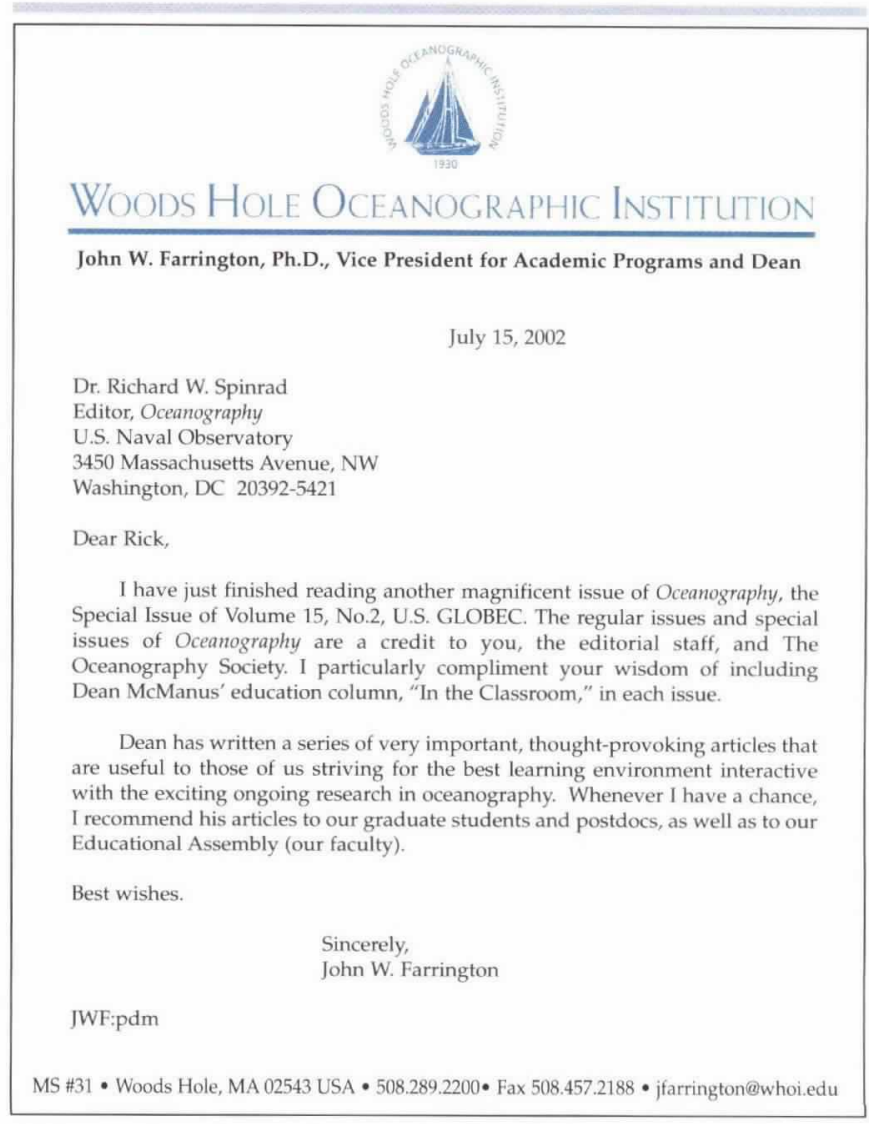

